\title{
Desenvolvimento de salsicha de carne de frango com baixo teor de gordura
}

\section{Development of low fat chicken meat sausage}

\author{
Cláudia Emilia Teixeira, ${ }^{*}$ Sérgio Mano, ${ }^{* *}$ Henrique Silva Pardi, ${ }^{* *}$; Mônica Queiroz de Freitas**
}

\begin{abstract}
Resumo
Com o objetivo de elaborar salsichas de carne de frango com baixo teor de gordura (low fat) com características sensoriais aceitáveis, produziram-se sete produtos ( $\mathrm{F} 1, \mathrm{~F} 2, \mathrm{~F} 3, \mathrm{~F} 4, \mathrm{~F} 5, \mathrm{~F} 6$ e controle) variando-se a quantidade de proteína isolada de soja (PIS) e de água nas formulações experimentais, a saber: 0, 2, 4, 6, 8, 3 e $0 \%$ e 32, 30, 28, 26, 24, 10 e $10 \%$ respectivamente. Armazenaram-se as amostras a $7 \pm 2^{\circ} \mathrm{C}$ durante 28 dias e realizaram-se análises da composição centesimal, pH, valor calórico, contagem de mesófilos e psicrotróficos, além do rendimento após o cozimento em estufa e avaliação sensorial (teste de aceitabilidade). Os dados da análise sensorial foram avaliados por análise de variância (ANOVA) assumindo um teste nãoparamétrico de Kruskal-Wallis. Os resultados das análises demonstraram que quanto maior for o teor de água e menor o teor de gordura, maior será a umidade, e, conseqüentemente, menor o rendimento pós-cozimento. A PIS conferiu maior teor protéico às amostras, elevando também o teor de cinzas. Na avaliação sensorial, constatou-se que quanto menor o teor de gordura e maior o de PIS adicionada, menor será a aceitabilidade do produto. Entretanto, a maior adição de água conferiu melhores pontuações na avaliação sensorial. As amostras F1 (2,2\% de gordura e $32 \%$ de água), e a controle receberam as maiores pontuaçõ̃es. Em relação às análises microbiológicas, verificou-se que quanto maior a adição de água, menor a vidade-prateleira. Com base nos resultados obtidos, pode-se concluir que é possível produzir salsichas sensorialmente aceitas com $2 \%$ de gordura, 30 a $32 \%$ de água adicionada e $2 \%$ de PIS.
\end{abstract}

Palavras-chave: frango, salsicha, low fat, proteína isolada de soja, análise sensorial.

\begin{abstract}
The objective of the present work was to produce low fat chicken sausages to assist certain population groups. It was produced seven products with different formulations, the first one was a control formulation and six with variations in the amount of isolated soy protein (ISP) and water, 0, 2, 4, 6, 8, 3 and $0 \%$ and $32,30,28,26,24,10$ and $10 \%$, respectively. The samples were stored to $7 \pm 2^{\circ} \mathrm{C}$ for 28 days and they took place analyses of the centesimal composition, $\mathrm{pH}$, caloric value, mesophylic and psychrotrophic counts, besides, yield after heat processing and sensory evaluation (acceptability test). The data of the sensorial analysis were appraised for variance analysis (ANOVA) assuming a test non-parametric of Kruskal-Wallis. The results of the analyses demonstrated that added water levels increased in low fat, percentage of moisture was increased, consequently percentage of yield decreased. ISP provided high levels of protein to the samples, also elevating the levels of ashes. In the sensory evaluation, it was verified that low levels of fat and high levels of ISP, decreased the acceptability of the product. However, high levels of water, provided better scores in the sensory evaluation. The samples F1 (2,2\% of fat and $32 \%$ of water) and the controls received highest sensory scores. In relation to the microbiological analyses, demonstrated when added water levels increased the shelflife decreased. The results of this work end that it is possible to produce sausages with $2 \%$ of fat, $32-30 \%$ of added water and $2 \%$ of ISP and sensory acceptable.
\end{abstract}

Keywords: chicken, sausage, low fat, isolated soy protein, sensory analysis.

\section{Introdução}

Tem crescido muito nos últimos anos o mercado de consumidores adeptos a dietas mais saudáveis, alimentos com menos calorias, gordura saturada e colesterol. Muitos anos de educação e informação levaram o consumidor a um posicionamento mais saudável em relação à sua alimentação, sobretudo a uma conscientização crítica no que diz respeito à qualidade dos alimentos. O consumidor passou a ver na alimentação sadia uma forma de contribuição para a boa saúde e o seu bem-estar. Além disso, a boa alimentação tem um significado econômico, na medida em que ela é fator de redução de custos para a saúde pública (Wirth, 1993). Visando atender este novo e potencial mercado, as indústrias têm-se empenhado em desenvolver produtos cárneos com menor teor de gordura.

Hoogenkamp (1989) afirma que, usando tecnologia adequada, é possível fabricar salsichas $90 \%$ fat free. Esse produto, de acordo com o autor, precisa ser processado com $2 \%$ a $2,4 \%$

* Programa de Pós-Graduação em Higiene Veterinária e Processamento Tecnológico de Produtos de Origem Animal - Faculdade de Veterinária - Universidade Federal Fluminense. Rua Vital Brazil Filho, 64, CEP 24230-340. c.emilia@ibest.com.br

** Departamento de Tecnologia dos Alimentos - Faculdade de Veterinária - Universidade Federal Fluminense. Rua Vital Brazil Filho, 64, CEP 24230-340. mtasbm@vm.uff.br 
de proteína não-cárnea. Combinando-se proteínas nãocárneas, produzem-se alimentos que se encaixam na categoria saudável e que podem ser comercializados a custos aceitáveis.

Produtos cárneos com teor reduzido de gordura, como salsichas, requerem diferentes tecnologias quando comparados com produtos convencionais, pois a gordura tem uma importante influência na textura. É possível, com modernas tecnologias, produzir salsichas com $10 \%$ de gordura e características sensoriais aceitáveis (Wirth, 1988).

O mesmo autor menciona que, na tecnologia para obtenção destes produtos, a gordura é substituída por proteína e água, e os problemas encontrados são: capacidade da matériaprima de ligar a água e a mudança evidente do flavor. Normalmente, alguns condimentos ficam com sabor muito acentuado se colocados na mesma quantidade dos produtos convencionais na formulação, pois devido ao alto teor de água e baixo teor de gordura, estes ficam mais concentrados. Além disso, a gordura absorve e mascara o sabor dos condimentos, sendo necessário ajustar as quantidades destes para os novos produtos. A redução da gordura também faz com que o sabor do sal fique mais evidente, sendo necessário diminuir sua concentração de $2 \%$ para $1 \%$.

A adição de água somente é válida se esta for capaz de ficar ligada à proteína após todo o processamento. Tratamentos mecânicos como a pré-mistura, massageamento e tempo de adição de gordura e água, têm sido utilizados para melhorar a capacidade de ligação água/proteína e proteína/proteína. Porém, como afirma Claus et al. (1990), geralmente há a necessidade do uso de outros ingredientes para melhorar as propriedades de ligação e estabilidade da emulsão.

Os mesmos autores, ao trabalharem com salsichas low fat com $10 \%$ de gordura e $30 \%$ de água adicionada, concluíram que os produtos apresentaram pouca capacidade para manter a água ligada, com conseqüentes perdas no cozimento e exsudação na embalagem. Na análise centesimal, a umidade dos pro-dutos low fat ficou em torno de $74 \%$ e a controle em $56 \%$. A pouca capacidade de ligação da água nos produtos com $30 \%$ de água adicionada é explicada pela diminuição da força iônica das proteínas, sendo que a adição de 3\% de sal pode aumentar a força iônica, porém essa quantidade de sal não é sensorialmente aceita. Entretanto, observaram, também, que as salsichas low fat apresentaram-se mais macias e com melhor textura em relação às controle devido à adição de água.

Keeton (1991) afirma que a proteína de soja é tradicionalmente utilizada em produtos cárneos convencionais, e com aumento da produção de produtos com baixo teor de gordura, a proteína de soja é uma opção como substituto da gordura. $\mathrm{O}$ mesmo autor produziu salsichas com $12 \%$ de gordura e 3,5\% de proteína isolada de soja. As salsichas apresentaram-se mais coesas e firmes, e com menor perda no cozimento em relação às controle $(30 \%$ de gordura), porém menos suculentas.

De acordo com Keeton (1994), as atitudes dos consumidores a respeito destes produtos variam, mas geralmente são bem aceitos se tiverem atributos sensoriais aceitáveis, preço razoável, algum mérito nutricional e não diferirem muito sensorialmente do produto tradicional.
Tendo em vista o interesse dos fabricantes na produção de alimentos com baixos teores de gordura, o objetivo do presente trabalho foi elaborar salsichas de carne de ave com baixo teor de gordura (low fat) com características sensoriais aceitáveis. Objetivou-se, também, avaliar o desempenho dos substitutos da gordura (proteína isolada de soja e água) e a vida-deprateleira das salsichas.

\section{Material e métodos}

As formulações e os produtos foram desenvolvidos na empresa Comave Comércio e Indústria Ltda. no município de Bom Jardim, no estado do Rio de Janeiro.

As análises físico-químicas, microbiológicas e sensoriais foram realizadas nos laboratórios do Departamento de Tecnologia de Alimentos da Faculdade de Veterinária da Universidade Federal Fluminense - UFF, Niterói, RJ.

Foram desenvolvidos sete produtos com diferentes formulações, sendo uma formulação controle e seis com variações na quantidade de proteína isolada de soja (PIS) e água.

A matéria-prima utilizada em todas as formulações low fat foi o filé de coxa sem pele e gordura, e como substitutos da gordura adicionou-se PIS em base seca, amido (fécula de mandioca), carragena e água.

A formulação controle (F7) foi elaborada seguindo o Regulamento Técnico de Identidade e Qualidade de Salsicha (Brasil, 1999). Produziu-se também um produto denominado light (F6) e outros cinco (F1, F2, F3, F4 e F5) denominados low fat. Todas as formulações podem ser encontradas na Tabela 1.

Tabela 1: Matérias-primas e ingredientes (\%) utilizados nas formulações F1, F2, F3, F4, F5, F6 (light) e F7 (controle)

\begin{tabular}{lrrrrrrr}
\hline \hline $\begin{array}{c}\text { Matérias-primas e } \\
\text { ingredientes }\end{array}$ & \multicolumn{1}{c}{$\mathrm{F} 1$} & $\mathrm{~F} 2$ & $\mathrm{~F} 3$ & $\mathrm{~F} 4$ & $\mathrm{~F} 5$ & $\begin{array}{c}\mathrm{F} 6 \\
\text { (light) }\end{array}$ & $\begin{array}{c}\mathrm{F} 7 \\
\text { (controle) }\end{array}$ \\
\hline Filé de coxa sem pele & 60,00 & 60,00 & 60,00 & 60,00 & 60,00 & 55,00 & 53,10 \\
CFMS & - & - & - & - & - & 20,00 & 20,00 \\
Pele & - & - & - & - & - & 5,00 & 3,00 \\
Toucinho & - & - & - & - & - & - & 9,00 \\
Sal & 1,00 & 1,00 & 1,00 & 1,00 & 1,00 & 1,00 & 1,00 \\
Água & 32,00 & 30,00 & 28,00 & 26,00 & 24,00 & 10,00 & 10,00 \\
Nitrito & 0,025 & 0,025 & 0,025 & 0,025 & 0,025 & 0,025 & 0,025 \\
Polifosfato & 0,25 & 0,25 & 0,25 & 0,25 & 0,25 & 0,25 & 0,25 \\
Eritorbato & 0,25 & 0,25 & 0,25 & 0,25 & 0,25 & 0,25 & 0,25 \\
PIS & - & 2,00 & 4,00 & 6,00 & 8,00 & 3,00 & - \\
Amido de mandioca & 2,00 & 2,00 & 2,00 & 2,00 & 2,00 & 2,00 & 2,00 \\
Carragena & 0,50 & 0,50 & 0,50 & 0,50 & 0,50 & - & - \\
Condimento pronto & 0,50 & 0,50 & 0,50 & 0,50 & 0,50 & 0,50 & 0,50 \\
Pimenta branca & 0,30 & 0,30 & 0,30 & 0,30 & 0,30 & 0,15 & 0,30 \\
Cebola em pó & 0,40 & 0,40 & 0,40 & 0,40 & 0,40 & 0,25 & 0,40 \\
Carmim & 0,10 & 0,10 & 0,10 & 0,10 & 0,10 & - & - \\
Ácido lático & 0,15 & 0,15 & 0,15 & 0,15 & 0,15 & 0,15 & 0,15 \\
Lactato & 2,50 & 2,50 & 2,50 & 2,50 & 2,50 & 2,50 & - \\
\hline \hline
\end{tabular}

CFMS - Carne de frango mecanicamente separada

PIS - Proteína isolada de soja

O filé de coxa foi desossado, retirou-se a pele e gordura e, posteriormente, foi congelado a $-25^{\circ} \mathrm{C}$ e mantido a $-18^{\circ} \mathrm{C}$ por aproximadamente sete dias. Na formulação controle foram utilizados, além do filé de coxa, toucinho da região lombar congelado e CFMS também congelada e mantida $\mathrm{a}-18^{\circ} \mathrm{C}$.

Inicialmente, triturou-se a carne no cutter com sal e metade da água com nitrito e polifosfato dissolvidos. Adicionou-se a 
seguir: PIS, condimentos, carmim, outra metade da água com o eritorbato dissolvido, amido, carragena e, por último, ácido lático e lactato. $\mathrm{A}$ água adicionada à massa encontrava-se à temperatura de $2^{\circ} \mathrm{C}$ e a temperatura final da massa no cutter não ultrapassou $10^{\circ} \mathrm{C}$.

Posteriormente, embutiram-se as salsichas em tripa artificial de celulose com $22 \mathrm{~mm}$ de diâmetro. A seguir, amarrou-se em gomos de $10 \mathrm{~cm}$, pesou-se para o controle do rendimento, pendurou-se em carrinhos apropriados e colocou-se em estufa.

O processo de cozimento em estufa realizou-se nos seguintes tempos e temperaturas: $50^{\circ} \mathrm{C}$ por 15 minutos com chaminé aberta (secagem), $60^{\circ} \mathrm{C}$ por 30 minutos com chaminé fechada (avermelhamento), aumento de $5^{\circ} \mathrm{C}$ a cada 5 minutos até o centro do produto atingir $72^{\circ} \mathrm{C}$ (cozimento propriamente dito). Convém lembrar que a temperatura da estufa não ultrapassou a temperatura de $85^{\circ} \mathrm{C}$.

A seguir, colocaram-se as salsichas em chuveiro até a temperatura interna atingir $40^{\circ} \mathrm{C}$. Pesaram-se as amostras para o controle do rendimento de cozimento e colocou-se em câmaras frigoríficas em temperatura de $3^{\circ} \mathrm{C}$ por três horas. Posteriormente retirou-se a tripa manualmente, os produtos foram embalados a vácuo e armazenados em temperatura de $7 \pm 2^{\circ} \mathrm{C}$ durante 28 dias.

No produto controle (F7), além do filé de coxa, utilizaram-se CFMS, toucinho e pele - também triturados no cutter seguindo-se a seqüência de adição: carne, CFMS, toucinho, sal, metade da água com nitrito e polifosfato dissolvidos, amido, condimentos, pele, outra metade da água com eritorbato dissolvido e ácido lático.

$\mathrm{Na}$ estufa, a salsicha controle seguiu tempos e temperaturas diferentes: $50^{\circ} \mathrm{C}$ por 20 minutos com a chaminé aberta (secagem), $60^{\circ} \mathrm{C}$ por 20 minutos com a chaminé fechada (avermelhamento), aumento de $5^{\circ} \mathrm{C}$ a cada 10 minutos até o centro do produto atingir $72^{\circ} \mathrm{C}$ (cozimento propriamente dito).

Ao final da elaboração das amostras, seguiu-se o armazenamento a $7 \pm 2^{\circ} \mathrm{C}$ durante 28 dias. Durante o referido período, colheram-se alíquotas em duplicata tanto para as análises físico-químicas como para as microbiológicas.

As análises de proteína, lipídeos e resíduo mineral fixo foram realizadas no $1^{\circ}$ e $28^{\circ}$ dias. A umidade determinou-se no $1^{\circ}, 7^{\circ}$, $14^{\circ}, 21^{\circ}$ e $28^{\circ}$ dias. Estas análises seguiram o método descrito pelo Laboratório Nacional de Referência Animal (Brasil, 1981).

A análise de $\mathrm{pH}$ realizou-se no $1^{\circ}, 7^{\circ}, 14^{\circ}, 21^{\circ}$ e $28^{\circ}$ dias pelo método potenciométrico (Brasil, 1981).

O cálculo do valor calórico dos produtos foi obtido multiplicando-se o teor de lipídios por 9,1 Kcal/g, e o teor de proteínas por $4,1 \mathrm{Kcal} / \mathrm{g}$, somando-se posteriormente os resultados (Gaspar et al., 1997).

Para avaliação do rendimento, pesaram-se os produtos antes e depois do cozimento, e o cálculo realizado por diferença de peso.

Escolheu-se para a avaliação sensorial o teste de aceitabilidade, o qual foi realizado por um grupo de 53 julgadores não-treinados.

Os produtos foram aquecidos, cortados e apresentados aos provadores em quantidades representativas em pratos plásticos, com as amostras devidamente codificadas de acordo com o método recomendado pelo Ital (1982). Distribuíram- se fichas contendo pontuações variando de "muito bom" a "inaceitável" para avaliar a aceitabilidade do produto pedindose aos provadores que marcassem nas referidas fichas as respostas que melhor refletissem seu julgamento em relação à aceitação do produto.

A contagem de bactérias heterotróficas aeróbias mesófilas e psicrotróficas seguiu a metodologia descrita pelo Laboratório Nacional de Referência Animal (Brasil, 1981).

Os dados da análise sensorial foram avaliados por análise de variância (ANOVA) assumindo um teste não-paramétrico de Kruskal-Wallis. Nos demais resultados empregaram-se a análise estatística descritiva simples e comparação entre os tratamentos através de gráficos utilizando-se o software Excel.

\section{Resultados e discussão}

Em relação ao teor de umidade, os resultados médios das amostras encontram-se na Tabela 2 e suas variações estão representadas graficamente na Figura 1.

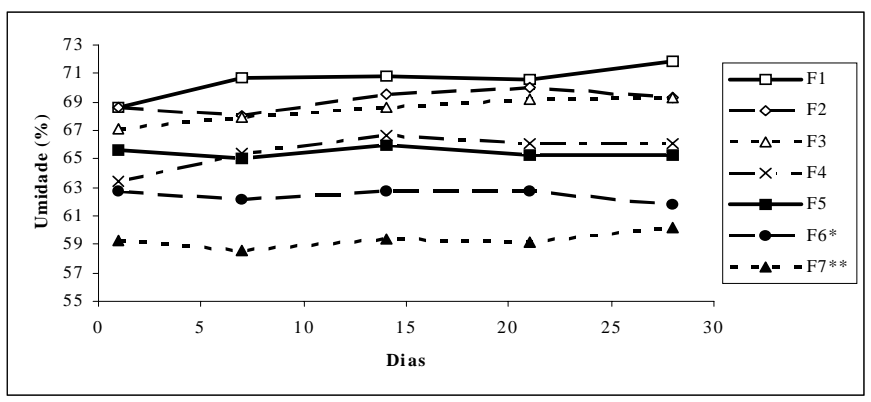

* Amostra considerada como light

** Amostra controle

Figura 1: Representação gráfica dos teores médios de umidade (\%) obtidos nos diferentes dias de análise das formulações com diferentes teores de proteína isolada de soja: F1 (0\%), F2 (2\%), F3 (4\%), F4 (6\%), F5 (8\%), F6 (3\%) e F7 (0\%).

Pode-se observar na Tabela 2 que os teores de umidade das formulações $\mathrm{F} 1$ a F6 variaram entre si e também em relação à amostra controle (F7), sendo que as formulações F1, F2 e F3 apresentaram os maiores teores de umidade. Com exceção da F7 e da considerada amostra light (F6), as outras amostras tiveram um ligeiro aumento durante a armazenagem do $1^{\circ}$ ao 28 dia. As formulações low fat (F1, F2, F3, F4 e F5), apresentaram um ligeiro aumento da umidade durante a armazenagem, fato este explicado por diversos autores (Wirth, 1988; Claus et al., 1990; Shand et al., 1990) em função da pouca capacidade desses produtos de manter a água ligada devido à diminuição da força iônica das proteínas. Entretanto, Sarantópoulos e Oliveira (1994) concluem que a embalagem a vácuo, de uma maneira geral, diminui as perdas de umidade durante a armazenagem.

Observou-se, também, que o teor de umidade das amostras relacionou-se com a quantidade de água adicionada, isto é, quanto maior a quantidade de água na formulação, maior o teor de umidade, que variou de $32,30,28,26,24,10$ e $10 \%$ para as formulações F1, F2, F3, F4, F5, F6 e F7 respectivamente. Os resultados de umidade obtido neste presente trabalho não diferiram dos resultados encontrados por Claus e Hunt (1991), onde salsichas com 30\% de água adicionada apresentaram $72 \%$ de umidade.

Com relação às análises de proteína, os dados encontram-se na Tabela 2 e suas variações estão representadas na Figura 2. 
Os resultados indicaram que quanto maior a quantidade de proteína isolada de soja (PIS) adicionada, maior o teor de proteína. Achados que estão de acordo com os de Wirth (1988), que opina que salsichas com baixo teor de gordura têm 3\% a $4 \%$ a mais de proteína devido ao uso de substitutos da gordura à base de proteína não-cárnea. Porém, na amostra controle (F7), onde não se adicionou PIS, o teor de proteína (16,8\%) não apresentou resultados muito diferentes das amostras F1, F2, F3 e F6 ( 15,7\%), fato que pode ser explicado devido à adição, nesta formulação, de CFMS.

Como se observa na Tabela 2, com exceção da amostra F6, ocorreu uma diminuição dos valores protéicos quando se compararam os resultados do $1^{\circ}$ e $28^{\circ}$ dia. Possivelmente, tal diminuição ocorreu devido ao aumento da umidade das amostras, com conseqüente redução do teor de proteína. Esta suposição é corroborada pelo fato da umidade da amostra F6 não haver tido variações significativas e, conseqüentemente, não influenciando nos teores protéicos.

Tabela 2: Teores médios de umidade, proteína, lipídios, resíduo mineral fixo, em percentuais, valor calórico (Kcal/g) obtidos no 1ํ e 28 dia de análise e rendimento (\%) no 1ㅇ dia de análise das formulações com diferentes teores de proteína isolada de soja: F1 (0\%), F2 (2\%), F3 (4\%), F4 (6\%), F5 (8\%), F6 (3\%) e F7 (0\%)

\begin{tabular}{ccrrrrrrr}
\hline \hline & Dias & F1 & F2 & F3 & F4 & F5 & F6 $^{*}$ & F7 $^{\star *}$ \\
\hline \multirow{2}{*}{ Umidade } & $\mathbf{1}$ & 68,7 & 68,6 & 67,2 & 63,4 & 65,7 & 62,8 & 59,3 \\
& $\mathbf{2 8}$ & 71,9 & 69,3 & 69,3 & 66,1 & 65,3 & 61,8 & 60,2 \\
Proteína & $\mathbf{1}$ & 14,4 & 15,3 & 17,1 & 20,8 & 23,7 & 16,0 & 16,8 \\
& $\mathbf{2 8}$ & 13,8 & 14,7 & 14,7 & 20,2 & 21,6 & 16,9 & 16,1 \\
Lipídios & $\mathbf{1}$ & 2,2 & 2,2 & 1,6 & 1,4 & 1,2 & 9,1 & 16,4 \\
& $\mathbf{2 8}$ & 2,2 & 2,0 & 1,7 & 1,5 & 1,2 & 9,4 & 16,0 \\
Resíduo & $\mathbf{1}$ & 3,9 & 3,3 & 4,0 & 3,0 & 3,7 & 3,1 & 3,9 \\
Mineral Fixo & $\mathbf{2 8}$ & 4,0 & 3,0 & 3,9 & 2,9 & 4,0 & 3,3 & 4,0 \\
Valor & $\mathbf{1}$ & 79,4 & 82,3 & 84,2 & 97,4 & 107,9 & 148,5 & 218,1 \\
Calórico & $\mathbf{2 8}$ & 76,8 & 78,5 & 76,0 & 96,8 & 99,1 & 154,9 & 211,6 \\
Rendimento & - & 75,6 & 76,88 & 81,7 & 85,52 & 82,12 & 84,03 & 86,6 \\
\hline \hline
\end{tabular}

* Amostra considerada como light

** Amostra controle

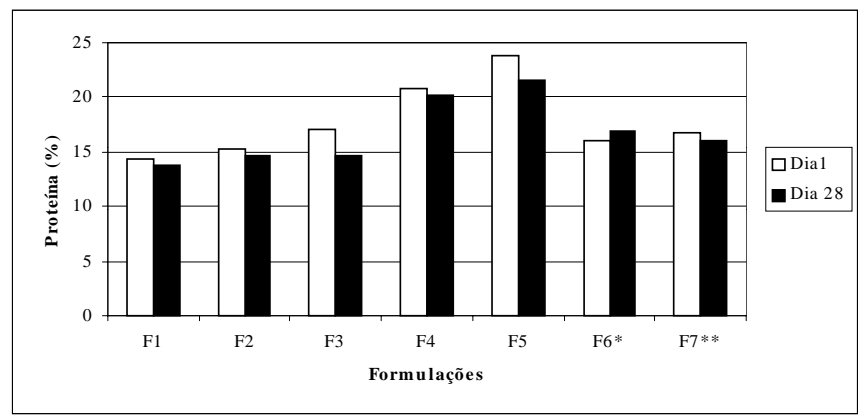

* Amostra considerada como light

** Amostra controle

Figura 2: Representação gráfica dos teores médios de proteína (\%) obtidos no 1ํ e 28 dia de análise das formulações com diferentes teores de proteína isolada de soja: F1 (0\%), F2 (2\%), F3 (4\%), F4 (6\%), F5 (8\%), F6 (3\%) e F7 (0\%).

Os dados do teor de lipídios das amostras estão na Tabela 2 e a respectiva representação gráfica nas Figuras 3 e 4.
De acordo com os resultados, como se observa na Tabela 2, as amostras apresentaram diferenças nos teores de lipídeos entre as formulações low fat (F1, F2, F3, F4 e F5). Tais variações provavelmente ocorreram devido às variações na matéria-prima (filé de coxa sem pele), em função da toalete realizada, como pode ser visualizado na Figura 3. As pequenas diferenças dos resultados observados entre o $1^{\circ}$ e $28^{\circ}$ dia, ocorreram, possivelmente, devido às variações pertinentes às análises.

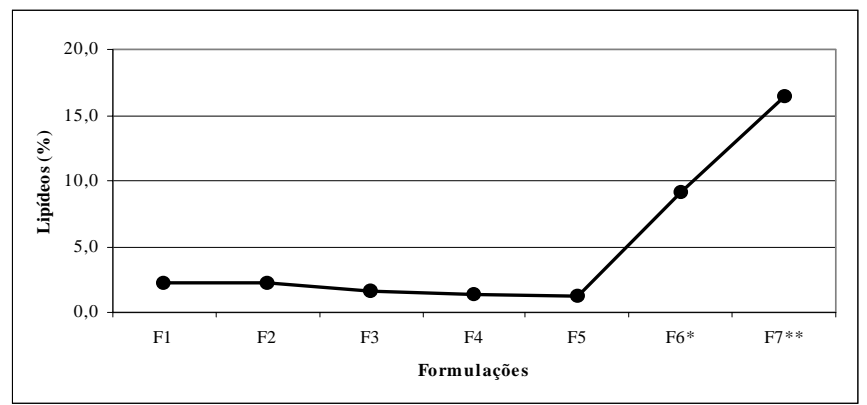

* Amostra considerada como light

** Amostra controle

Figura 3: Representação gráfica dos teores médios de lipídios (\%) obtidos no 10 dia de análise das formulações com diferentes teores de proteína isolada de soja: F1 (0\%), F2 (2\%), F3 (4\%), F4 (6\%), F5 (8\%), F6 (3\%) e F7 (0\%).

Barbut e Mittal (1995) constataram que produtos com baixo teor de gordura apresentaram maior teor de umidade. Esta relação está comprovada no presente trabalho quando se comparam estes respectivos valores na Tabela 2 , observandose principalmente os resultados do $1^{\circ}$ dia das amostras $\mathrm{F} 1$, F2, F3, F4, F5 comparando-as com a F6 e F7.

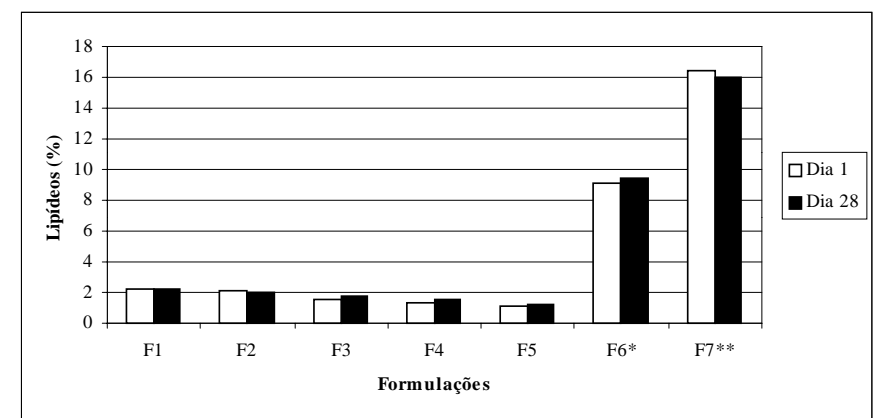

* Amostra considerada como light

** Amostra controle

Figura 4: Representação gráfica dos teores médios de lipídeos (\%) obtidos no $1^{\circ}$ e $28^{\circ}$ dia de análise das formulações com diferentes teores de proteína isolada de soja: $\mathrm{F} 1(0 \%), \mathrm{F} 2(2 \%), \mathrm{F} 3(4 \%), \mathrm{F} 4(6 \%), \mathrm{F} 5(8 \%), \mathrm{F} 6$ (3\%) e F7 (0\%).

Os valores obtidos nas análises do resíduo mineral fixo (cinzas) variaram entre as amostras, e entre o $1^{\circ}$ e $28^{\circ} \mathrm{dia}$, somente não ocorrendo entre a F1 e F7 (Tabela 2). O aumento do teor de cinzas observado nas amostras F2, F3, F4, F5 e F6 certamente deve-se ao fato de a PIS possuir $5 \%$ de cinzas, como explicam Pardi et al. (1995). Entretanto, a variação ocorrida entre as amostras não está bem esclarecida, ocorrendo provavelmente devido a variações existentes nas análises. As amostras F1 e F7 não variaram entre si por não conterem PIS na formulação. A Figura 5 apresenta graficamente os resultados das análises. 


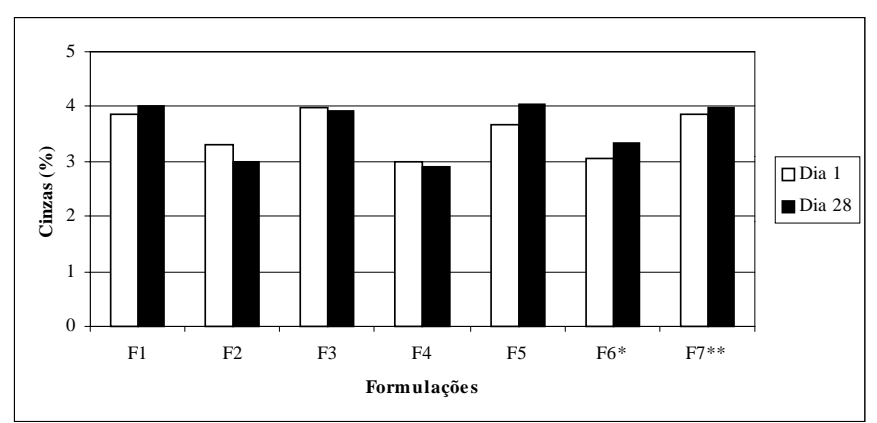

* Amostra considerada como light

** Amostra controle

Figura 5: Representação gráfica dos teores médios de resíduo mineral fixo (\%) obtidos no 1 o e 28 을 dia de análise das formulações com diferentes teores de proteína isolada de soja: F1 (0\%), F2 (2\%), F3 (4\%), F4 (6\%), F5 (8\%), F6 (3\%) e F7 (0\%).

Os resultados dos valores de $\mathrm{pH}$ nas amostras F1, F2, F3, F4, F5 e F7 diminuíram com o passar dos dias, até um mínimo alcançado no $21^{\circ}$ dia, voltando a aumentar no $28^{\circ}$ dia (Tabela 4, Figura 6). A amostra F6 apresentou um comportamento semelhante às demais amostras, entretanto, com valores superiores. Provavelmente a diminuição do $\mathrm{pH}$ ocorreu devido à influência da embalagem a vácuo. Este fato é explicado por Sarantópoulos e Oliveira (1994), os quais afirmam que, na embalagem a vácuo e na ausência de oxigênio, predominam as bactérias láticas, as quais causam menor alteração na qualidade das carnes, mesmo em altas contagens, porém abaixam o pH mesmo quando o produto já está no final de sua vida útil.

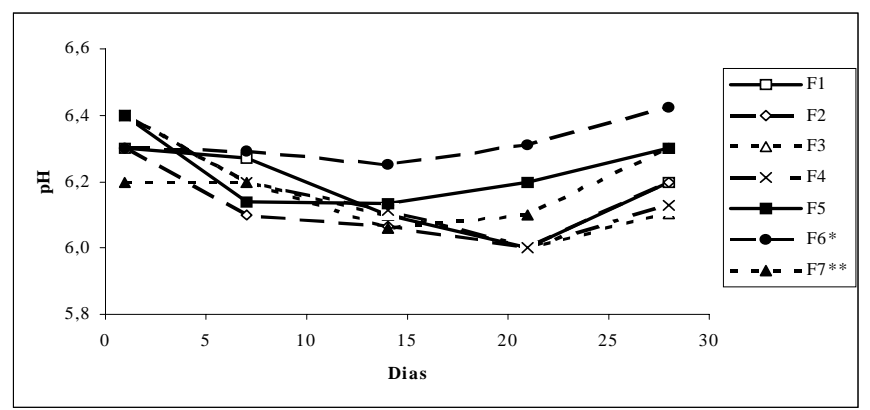

* Amostra considerada como light

** Amostra controle

Figura 6: Representação gráfica dos valores de $\mathrm{pH}$ obtidos nos diferentes dias de análise das formulações com diferentes teores de proteína isolada de soja: F1 (0\%), F2 (2\%), F3 (4\%), F4 (6\%), F5 (8\%), F6 (3\%) e F7 (0\%).

Os resultados do valor calórico variaram nas amostras $\mathrm{F} 1$, F2, F3, F4 e F5 em função do aumento do teor de proteína, pois este cálculo baseia-se no teor de proteína e lipídios do produto (Tabela 2, Figura 7). Os lipídios diminuíram, porém a proteína aumentou devido à adição de PIS.

As amostras F6 (light) e F7 (controle) apresentaram os maiores teores de valor calórico (Tabela 2). A amostra F6 apresentou o menor teor de gordura em relação a F7 (Tabela 2). A amostra F7 obteve os maiores teores de valor calórico devido aos lipídios da pele, CFMS e toucinho.

As diferenças ocorridas entre as amostras no $1^{\circ}$ e $28^{\circ}$ dias ocorreram devido às variações na análise de lipídios e proteínas comentadas anteriormente, o que, conseqüentemente, ocasionou a variação dos resultados no valor calórico. Os valores obtidos neste trabalho assemelham-se aos resultados obtidos por Wirth (1991) concluindo que produtos com 15\% de lipídios, $70 \%$ de carne magra e proteína ao redor de $16 \%$, possuem valor calórico de 100 a $200 \mathrm{kcal} / \mathrm{g}$.

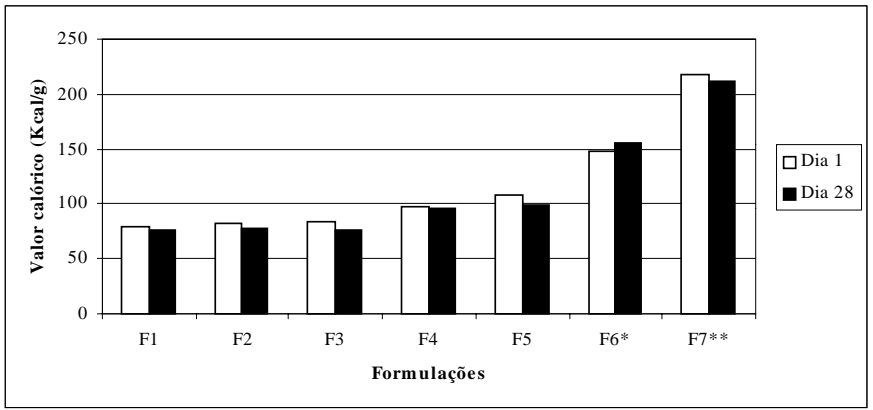

* Amostra considerada como light

** Amostra controle

Figura 7: Representação gráfica do valor calórico (Kcal/g) obtido no $1^{\circ}$ e $28^{\circ}$ dia de análise das formulações com diferentes teores de proteína isolada de soja: F1 (0\%), F2 (2\%), F3 (4\%), F4 (6\%), F5 (8\%), F6 (3\%) e F7 (0\%).

Os resultados do rendimento das diversas formulações são apresentados na Tabela 2 e melhor visualizados na Figura 8. Ao comparar-se o rendimento com os teores de água adicionados (Tabela 1), observa-se que quanto maior o teor de água, menor foi o rendimento obtido, fato explicado pelas perdas ocorridas durante o cozimento. Pôde-se observar uma variação entre as amostras F1, F2, F3 e F4 e também destas em relação à amostra controle e light, variações estas ocorridas em função da quantidade de água adicionada.

A F7 apresentou o melhor rendimento, certamente devido à pouca quantidade de água na formulação associada à adição de gordura. O rendimento da amostra F6, mesmo possuindo uma quantidade maior de gordura, foi inferior ao da amostra $\mathrm{F} 4$, o que se explica por esta última possuir uma maior quantidade de PIS, o que ocasiona maiores retenções de água e, conseqüentemente, maiores rendimentos. A amostra F5 obteve rendimento menor que a F4, apesar de possuir menor quantidade de água e maior teor de PIS adicionado. Os resultados encontrados concordam com os citados por Claus (1991), Hakerma (1997), Ahmed et al. (1990) e Keeton (1994) e Rice et al. (1989), que afirmam que quanto maior o teor de PIS, maior o rendimento do cozimento.

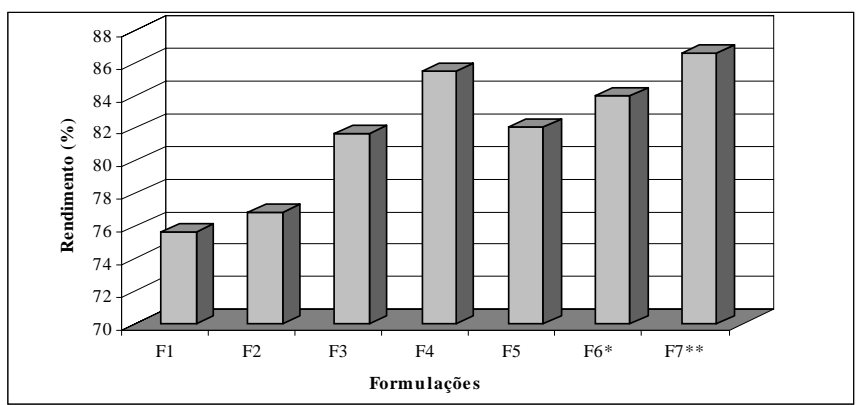

* Amostra considerada como light

** Amostra controle

Figura 8: Representação gráfica dos rendimentos (\%) obtidos na produção das formulações com diferentes teores de proteína isolada de soja: F1 (0\%), F2 (2\%), F3 (4\%), F4 (6\%), F5 (8\%), F6 (3\%) e F7 (0\%). 
Em relação à avaliação sensorial (Tabela 3, Figura 9), os resultados demonstram que a amostra $\mathrm{F} 1$ não diferiu da F7 $(P>0,05)$, diferindo estatisticamente das demais amostras $(\mathrm{P}<0,001)$. Devido à amostra $\mathrm{F} 1$ possuir uma maior quantidade de água adicionada e não ter tido a adição de PIS, obtiveramse características sensoriais próximas à amostra controle (F7). Além disso, a amostra F1, quando comparada com as amostras low fat, apresentou um maior teor de gordura.

Tabela 3: Resultados da avaliação sensorial das diferentes formulações em relação aos teores percentuais de proteína isolada de soja (PIS), lipídios e umidade

\begin{tabular}{cccccccc}
\hline \hline & $\mathbf{F 1}$ & $\mathbf{F 2}$ & $\mathbf{F 3}$ & $\mathbf{F 4}$ & $\mathbf{F 5}$ & $\mathbf{F 6}^{*}$ & F7 $^{\text {** }}$ \\
\hline $\begin{array}{c}\text { Análise } \\
\text { Sensorial }\end{array}$ & $8,5^{\mathrm{a}} \pm 0,8$ & $6,9^{\mathrm{be}} \pm 1,6$ & $5,5^{\mathrm{c}} \pm 1,0$ & $4,7^{\mathrm{cd}} \pm 2,2$ & $3,0^{\mathrm{d}} \pm 2,3$ & $5,4^{\mathrm{bc}} \pm 2,0$ & $7,8^{\mathrm{ae}} \pm 0,8$ \\
\hline PIS & 0 & 2 & 4 & 6 & 8 & 3 & 0 \\
Lipídios & 2,2 & 2,2 & 1,6 & 1,4 & 1,2 & 9,1 & 16,4 \\
Umidade & 68,7 & 68,6 & 67,2 & 63,4 & 65,7 & 62,8 & 59,3 \\
\hline \hline
\end{tabular}

* Amostra considerada como light

** Amostra controle

Obs. Valores da análise sensorial seguidos de letras iguais não diferem entre si ao nível de $1 \%$ de probabilidade segundo o teste de Kruskal-Wallis.

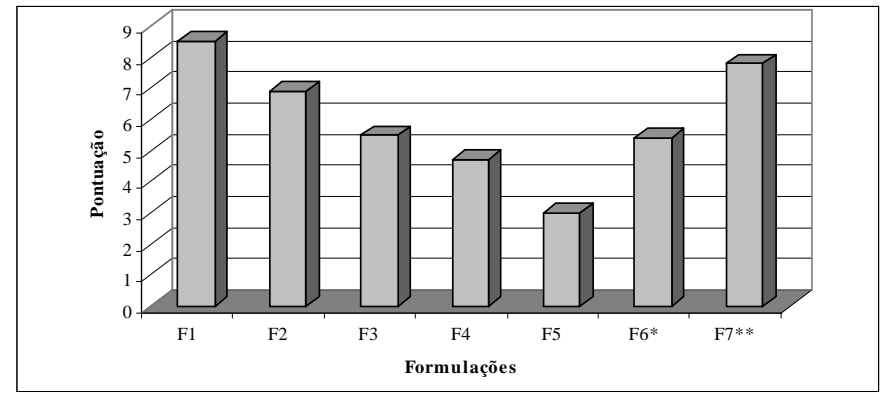

* Amostra considerada como light

** Amostra controle

Figura 9: Representação gráfica dos resultados da avaliação sensorial das diferentes formulações em relação aos teores percentuais de proteína isolada de soja: F1 (0\%), F2 (2\%), F3 (4\%), F4 (6\%), F5 (8\%), F6 (3\%) e F7 (0\%).

A amostra F2 não apresentou diferenças significativas em relação a F6 e F7 $(P>0,05)$, de acordo com a análise sensorial, mas diferiu em relação às demais amostras $(P<0,001)$, provavelmente devido a possuírem baixos teores de PIS adicionado e a F2 possuir um alto teor de umidade, ficando com as características sensoriais próximas das amostras F6 e F7.

A amostra F3 não diferiu significativamente da F4 e F6 $(P>0,05)$, diferindo das demais amostras $(P<0,001)$ devido às amostras F3 e F4 possuírem teor de gordura similares e as F3 e F6 terem sido adicionadas de PIS em quantidades similares.

$\mathrm{O}$ produto $\mathrm{F} 4$ não apresentou diferenças significativas entre os produtos $\mathrm{F} 3$, F6 e F5 $(\mathrm{P}>0,05)$, diferindo dos demais produtos $(P<0,001)$. Em relação à amostra $F 5$, esta não diferiu da amostra F4, possivelmente por ambas possuírem baixos teores de gordura e altos teores de PIS, diminuindo assim a aceitabilidade. Esta amostra (F5) apresentou diferenças significativas $(P<0,001)$ quando comparadas às demais, apresentando assim, a menor pontuação, provavelmente devido ao alto teor de PIS adicionado (8\%) e baixo teor de gordura $(1,2 \%)$.
O produto light (F6) não apresentou diferenças significativas em relação às amostras F2, F3 e F4 $(P>0,05)$, porém diferiu das demais $(P<0,001)$. Tais diferenças podem ser explicadas devido aos valores aproximados de PIS, e, devido ao fato de não utilizar-se julgadores treinados, estes não perceberam as pequenas diferenças que certamente ocorreram.

A amostra controle (F7) não diferiu significativamente das F1 e F2 $(P>0,05)$, diferindo das demais amostras $(P<0,001)$. As amostras F1 e F2 obtiveram resultados próximos aos da amostra controle, devido, provavelmente, ao baixo teor de PIS e alta quantidade de água, conferindo assim, características sensoriais aceitáveis às amostras.

Quanto menor o teor de gordura, menor a aceitabilidade das amostras, assim como, quanto maior o teor de PIS, menor a aceitação. $\mathrm{O}$ teor de PIS adicionado foi mais determinante do que o teor de gordura na aceitabilidade dos produtos e como os julgadores não foram treinados, pequenas diferenças não foram percebidas. A adição de 4, 6 e principalmente $8 \%$ de PIS conferiu aos produtos uma consistência "borrachuda" e seca.

Os resultados encontrados no presente trabalho estão de acordo com Macmindes (1991), Hakerma (1997) e Keeton (1991), que concluíram que $3,5 \%$ de PIS em salsichas low fat diminuiu a suculência. Porcentagens maiores que $2 \%$ de PIS, acarretaram produtos sensorialmente indesejáveis e excessivamente duros, resultados estes que estão de acordo com os encontrados por Keeton (1994) e Lemos (1998), os quais afirmam que a quantidade ideal de PIS é $2 \%$.

Com a diminuição do teor de gordura, houve uma diminuição da suculência e da palatabilidade das amostras. Estes achados estão de acordo com os de Pearson et al. (1987), Hakerma (1997) e Pardi et al. (1995) os quais concluíram que a gordura exerce grande influência no sabor, consistência e suculência, ou seja, quanto menor o teor de gordura, menor a aceitabilidade.

A amostra $\mathrm{F} 1$ (32\% de água adicionada) e a F7 (10\% de água adicionada) apresentaram as maiores pontuações no teste de aceitabilidade, porém a F7 (controle) apresentou menor pontuação que a F1, podendo ser explicado devido à adição de toucinho, CFMS e pele, os quais conferiram uma quantidade excessiva de gordura, tendo uma menor aceitabilidade. Estes resultados estão de acordo com Frederick et al. (1994), que em seu trabalho concluíram que a amostra com $35 \%$ de água adicionada e a controle apresentaram as maiores pontuações na avaliação sensorial.

Maiores quantidades de água adicionada determinaram maior aceitabilidade, possivelmente devido à consistência macia e aumento da suculência. Estes resultados concordam com os de Claus et al. (1990) e Ahmed et al. (1990), os quais concluíram que as salsichas com maiores teores de água ficaram mais suculentas e macias.

As amostras F1 e F2 apresentaram sabor salgado acentuado, apesar de possuir na formulação somente $1 \%$ de sal, porém, observou-se que este não foi determinante na aceitabilidade. Esta característica, existente nestes produtos, é explicada por Wirth (1988), pois devido ao alto teor de água e baixo teor de gordura, os condimentos ficam mais concentrados. Porém, o mesmo não aconteceu com as amostras F3, F4 e F5, que apesar do baixo teor de gordura, foram adicionadas de 4, 6 e 
$8 \%$ de PIS respectivamente, o que provavelmente, mascarou o sabor salgado.

De acordo com os resultados, é possível produzir salsichas com até $2 \%$ de gordura sensorialmente aceitas, quando comparadas com a amostra controle, discordando assim de Pearson et al. (1987) e Lemos (1998) os quais afirmam que, o máximo possível de gordura para fabricação destes produtos com boa aceitação pelo consumidor, é de $10 \%$.

Os resultados da contagem de mesófilos (Tabela 4, Figura 10) demonstram que, apesar da quantidade de água adicionada nas amostras F1, F2, F3 e F5, estas alcançaram contagens de no máximo $6,3 \times 10^{5}$ UFC/g em 28 dias de armazenagem a $7 \pm 2{ }^{\circ} \mathrm{C}$, sendo, portanto, de acordo com Franco e Landgraf (1996), consideradas aptas ao consumo sob o ponto de vista microbiológico, fato este provavelmente associado à adição de lactato.

Observou-se que as contagens das amostras low fat (de F1 a F5), de uma maneira geral, com exceção da amostra F4, aumentaram ordenadamente à medida que o teor de água adicionada aumentava. Estes resultados estão de acordo com Keeton (1994), que relatou que quanto maior a adição de água, menor a vida-de-prateleira.

Tabela 4: $\mathrm{pH}$, contagem de bactérias heterotróficas aeróbias mesófilas (CBHAM) e psicrotróficas (CBHAP) (Log UFC/g) obtidos nos diferentes dias de análise das formulações com diferentes teores de proteína isolada de soja: $\mathrm{F} 1(0 \%), \mathrm{F} 2$ $(2 \%)$, F3 (4\%), F4 (6\%), F5 (8\%), F6 (3\%) e F7 (0\%).

\begin{tabular}{ccccccccc}
\hline \hline & Dias & F1 & F2 & F3 & F4 & F5 & F6 $^{*}$ & F7 $^{\star \star}$ \\
\hline \multirow{5}{*}{ pH } & $\mathbf{1}$ & 6,3 & 6,3 & 6,4 & 6,4 & 6,4 & 6,3 & 6,2 \\
& $\mathbf{7}$ & 6,3 & 6,1 & 6,2 & 6,2 & 6,1 & 6,3 & 6,2 \\
& $\mathbf{1 4}$ & 6,1 & 6,1 & 6,1 & 6,1 & 6,1 & 6,3 & 6,1 \\
& $\mathbf{2 1}$ & 6,0 & 6,0 & 6,0 & 6,0 & 6,2 & 6,3 & 6,1 \\
& $\mathbf{2 8}$ & 6,2 & 6,2 & 6,1 & 6,1 & 6,3 & 6,4 & 6,3 \\
\hline \multirow{5}{*}{ BHAM } & $\mathbf{1}$ & 3,4 & 3,4 & 2,3 & 2,5 & 3,4 & 3,2 & 3,3 \\
& $\mathbf{7}$ & 3,7 & 3,5 & 3,4 & 3,0 & 2,9 & 3,2 & 3,3 \\
& $\mathbf{1 4}$ & 3,5 & 3,2 & 4,1 & 4,8 & 4,0 & 3,8 & 4,4 \\
& $\mathbf{2 1}$ & 4,4 & 4,7 & 4,2 & 5,8 & 4,4 & 3,7 & 5,3 \\
& $\mathbf{2 8}$ & 5,8 & 5,3 & 4,5 & 7,2 & 4,0 & 4,0 & 6,3 \\
\hline \multirow{5}{*}{ CBHAP } & $\mathbf{1}$ & 1,7 & 1,5 & 1,7 & 1,8 & 1,6 & 0,0 & 2,4 \\
& $\mathbf{7}$ & 3,3 & 4,4 & 3,6 & 3,0 & 2,1 & 0,5 & 4,7 \\
& $\mathbf{1 4}$ & 3,7 & 4,5 & 5,1 & 6,0 & 3,4 & 2,2 & 5,5 \\
& $\mathbf{2 1}$ & 4,6 & 4,7 & 6,7 & 7,1 & 4,4 & 3,1 & 5,6 \\
& $\mathbf{2 8}$ & 6,5 & 4,5 & 7,0 & 7,2 & 4,5 & 3,2 & 5,5 \\
\hline \hline
\end{tabular}

* Amostra considerada como light

** Amostra controle

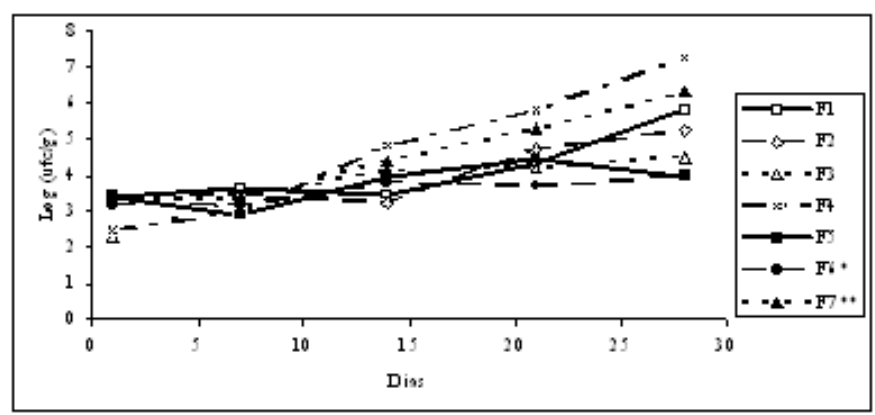

* Amostra considerada como light

** Amostra controle

Figura 10: Representação gráfica dos resultados da contagem de bactérias heterotróficas aeróbias mesófilas (Log UFC/g) obtidos nos diferentes dias de análise das formulações com diferentes teores de proteína isolada de soja: F1 (0\%), F2 (2\%), F3 (4\%), F4 (6\%), F5 (8\%), F6 (3\%) e F7 (0\%).
O produto F6 (10\% água), como era de se esperar, apresentou os melhores resultados, pois além de pouca adição de água, a adição de lactato provavelmente aumentou sua vida útil.

A amostra controle (F7) e a F4 apresentaram as maiores contagens microbianas, refletindo nas alterações das

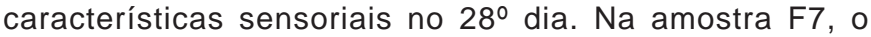
aumento das contagens ocorreu, provavelmente, devido à inexistência de lactato na formulação, visto que a sua adição controlou as contagens em relação às demais amostras. Outro fator que possivelmente colaborou com o ocorrido, pode estar relacionado com a qualidade microbiológica do toucinho, já que esta foi a única matéria-prima diferente adicionada. Esses resultados estão de acordo com Brewer et al. (1991), os quais concluíram que as amostras contendo $2 \%$ de lactato não atingiram contagens de $1,0 \times 10^{8} \mathrm{UFC} / \mathrm{g}$ até $24^{\circ}$ dia de armazenagem.

Os resultados do presente trabalho demonstraram que todas as amostras, com exceção das F4 e F7 não apresentaram alterações sensoriais, indicando boa qualidade sanitária das amostras, pois de acordo com Franco e Landgraf (1996), contagens acima de $1,0 \times 10^{6} \mathrm{UFC} / \mathrm{g}$ conferem alterações nas características sensoriais e sugerem abusos durante o armazenamento em relação ao binômio tempo/temperatura.

Nos resultados da contagem de psicrotróficos (Tabela 4, Figura 11), observou-se que a amostra F1, apesar de ser a amostra com a maior quantidade de água adicionada (32\%), sua maior contagem microbiana foi de $3,2 \times 10^{6} \mathrm{UFC} / \mathrm{g}$ após 28 dias de armazenamento.

As demais amostras, com exceção da F3 e F4, não chegaram a atingir contagens de $10^{6} \mathrm{UFC} / g$ após 28 dias de armazenamento, estando, de acordo com Franco e Landgraf (1996), sob o ponto de vista microbiológico, próprias para o consumo.

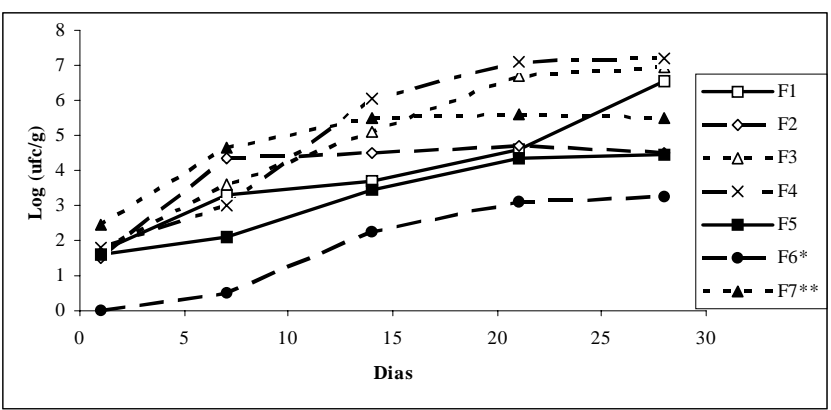

* Amostra considerada como light

** Amostra controle

Figura 11: Representação gráfica dos resultados da contagem de bactérias heterotróficas aeróbias psicrotróficas (Log UFC/g) obtidos nos diferentes dias de análise das formulações com diferentes teores de proteína isolada de soja: F1 (0\%), F2 (2\%), F3 (4\%), F4 (6\%), F5 (8\%), F6 (3\%) e F7 (0\%).

As amostras F3 e F4 obtiveram as maiores contagens e apresentaram alterações sensoriais no $21^{\circ}$ dia de armazenagem, com contagens de aproximadamente $10^{7}$ UFC/ g, indicando, de acordo com Franco e Landgraf (1996), sua deterioração.

A amostra F6, como observado nas contagens de mesófilos, obteve os melhores resultados, atingindo contagens de apenas $1,6 \times 10^{3} \mathrm{UFC} / \mathrm{g}$ após 28 dias, o que pode ser explicado pelas escassas contagens no $1^{\circ}$ dia, confirmando assim, que 
quanto menor a contagem inicial, maior será o período de vida útil.

\section{Conclusões}

De acordo com os resultados obtidos, demonstrou-se a possibilidade de produzir salsichas de carne de frango com $2 \%$ de gordura, com características sensoriais aceitáveis, desde que o processamento seja adaptado para produtos com baixo teor de gordura.

\section{Referências}

AHMED, P. O; MILLER, M. F; LYON, C. E; VAUGHTERS, H. M; REAGAN, J. O. Physical and sensory characteristics of low fat fresh pork sausage processed with various levels of added water. Journal of Food Science, v. 55, n. 3, p. 625-628, 1990.

BARBUT, S.; MITTAL G. S. Physical and sensory properties of reduced fat breakfast sausages. Journal of Muscle Foods, Connecticut, v. 6, p. 47-62, 1995.

BRASIL. Ministério da Agricultura. Secretaria Nacional de Defesa Agropecuária. Laboratório Nacional de Referência Animal (LANARA). Métodos Analíticos Oficiais para Controle de Produtos de Origem Animal e seus Ingredientes. I. Métodos microbiológicos. II. Métodos físicoquímicos. Aprovado pela Portaria oㅡo01, de 7/10/81. Brasília, DF, 1981.

Ministério da Agricultura. Secretaria Nacional de Defesa Agropecuária. Regulamento Técnico de Identidade e Qualidade de Salsicha - Anexo IV. 1999

Secretaria da Vigilância Sanitária, Portaria oㅜ 41, de 12 de maio de 1995. Diário Oficial, no 91, 1995.

BREWER, M. S.; MCKEITH, F.; MARTIN, S. E.;DALLMIER, A. W.; MEYER, J.; Sodium lactate effects on shelf-life, sensory and physical characteristics of fresh pork sausage. Journal of Food Science, v. 56 , n. 5, p. 1176-1178, 1991

CLAUS, J. R. Fat reduction in comminuted meat systems. Reciprocal Meat Conference Proceedings, Manhattan, v. 44, p. 93-98, 1991.

; HUNT, M. C. Low fat, high added water bologna formulated with texture modifying ingredients. Journal of Food Science, v. 56, n 3, p. 643-652, 1991.

; KASTNER, C. L.; KROPF, D. H. Low fat, high added water bologna effects of massing, pre-blending, and time of addition of water and fat on physical and sensory characteristics. Journal of Food Science, v. 55, n. 2, p. 338-341, 345, 1990.

FRANCO, B. D. G. M.; LANDGRAF, M. Microbiologia dos Alimentos, São Paulo: Atheneu, 1996.

FREDERICK, T. L.; MILLER, M. F.; TINNEY, K. S.;BYE, L. R.; RAMSEY, C. B. Characteristics of $95 \%$ lean beef german sausages varying in phosphate and added water. Journal of Food Science, v. 59, n. 3, p. 453-455, 1994.

GASPAR; BARROS, G. C.; SILVA, A. T.; NAGEL, W. S.; RÊGO, J. A. Salsichas tipo Viena com reduzido teor de gordura animal. Higiene Alimentar, v. 11, n. 52, p. 32-37, 1997.
A proteína isolada de soja, como substituto da gordura demonstrou contribuir para melhorar a capacidade de retenção de água e, quando adicionada até $3 \%$ conferiu às salsichas características sensoriais aceitáveis, sendo assim a sua adição determinante na aceitabilidade dos produtos.

A adição de água melhorou as características sensoriais, porém diminuiu o rendimento pós-cozimento e aumentou o teor de umidade das salsichas, com conseqüente diminuição da vida-de-prateleira.

HAKERMA, J. Agentes texturizadores para produtos cárneos processados. Engenharia de Alimentos, v. 2, n. 9, p. 17-21, 1997.

HOOGENKAMP, P. H. Low, lean and lite. Consumer concerns mean less salt, less fat. Meat Processing, October, p. 48-53, 1989.

INSTITUTO DE TECNOLOGIA DE ALIMENTOS (ITAL). Métodos Sensoriais e Físicos para avaliação de Alimentos e Bebidas. Principios e Aplicação. Campinas, 1982, 170 p.

KEETON, J. T. Fat substitutes and fat modification in processing. Reciprocal Meat Conference Proceedings, Manhattan, v. 44, p. 7991, 1991.

Low-fat meat products - technological problems with processing. Meat Science, v. 36, n. 1/2 p. 261-277, 1994.

LEMOS, A. L. S. C. Processamento de salsicha fat free. Seminário e Workshop Processamento de emulsionados e reestruturados. Instituto de Tecnologia de Alimentos, Campinas, p. 2-134, 1998.

MACMINDES, M. K. Application of isolated soy protein in low fat meat products. Food Technology, Dezembro, p. 61-64, 1991

PARDI, M. C.; SANTOS, I. F.; SOUZA, E.R.; PARDI, H. S. Ciência, higiene e tecnologia da carne.Goiânia: CEGRAF - UFG/Niterói: EdUFF, v. 2 , 1995, $1110 \mathrm{p}$.

PEARSON, A. M.; ASGHAR A.; GRAY J. I; BOOREN A M. Impact of fat reduction on palatability and consumer acceptance of processed meat. Reciprocal Meat Conference Proceedings, Minnesota, v. 40, p. 105113, 1987.

RICE, D. R; NEUFER P. A; SIPOS, E. F. Effects of soy protein blends, fat level and cooking methods on the nutrient retention of beef patties. Food Technology, Abril, p. 89-97, 1989.

SARANTÓPOULOS, C. I. G. L.; OLIVEIRA, L. M. Sistemas de embalagens plásticas para preservação de carne bovina e derivados. Revista Nacional da Carne, n. 206, p. 47-57, 1994.

SHAND P. J.; SCHIMIDT G. R.; MANDIGO R. W.; CLAUS J. R. New technology for low fat meat products. Reciprocal Meat Conference Proceedings, Mississipi, v. 43, p. 37-45, 1990.

WIRTH, F. Technologies for making fat-reduced meat products. Fleischwirtsch, v. 68, n. 9, p. 1153-1156, 1988

Reducing the fat and sodium content of meat products. Fleischwirtsch, v. 71, n. 3, p. 294-297, 1991.

. La reducción y el empleo de las substancias de curado en los productos cárnicos. Fleischwirtsc, 1993. 